\title{
Kenomotetisan dan Keideosinkretisan Makna Simbolis Pernikahan Adat Masyarakat Nusa Tenggara Timur dan Jambi: Perspektif Ekolinguistik Metaforis
}

\section{Nomothetics and Idiosyncratics of Simbolic Meanings of Traditional Marriage Equipments in East Nusa Tenggara and Jambi Societies: A Methaporical Ecolinguistic Perspective}

\author{
R. Kunjana Rahardi \\ Fransiskus O. Sanjaya \\ Nurfatimah
}
Program Studi Magister Pendidikan Bahasa Indonesia, Universitas Sanata Dharma Yogyakarta rahardi.kunjana@gmail.com

\begin{abstract}
ABSTRAK
Studi bahasa dalam kaitan dengan aspek-aspek sosial-budaya dalam perspektif ekolinguistik metaforis masih belum banyak dilakukan para peneliti Indonesia. Penelitian ekolinguistik metaforis ini difokuskan pada nilai-nilai simbolik nomotetik dan ideosinkretik pernikahan adat Provinsi Nusa Tenggara Timur dan Provinsi Jambi. Tujuan Penelitian ini adalah: (1) mendiskripsikan nilai-nilai nomotesis yang terdapat dalam peranti pernikahan adat masyarakat Provinsi Nusa Tenggara Timur (NTT) dan Provinsi Jambi; (2) mendeskripsikan nilai-nilai ideosinkretis yang terdapat dalam peranti pernikahan adat masyarakat Provinsi NT'T dan Provinsi Jambi? Data dikumpulkan dengan menerapkan metode simak dan metode cakap. Selain itu, data juga dikumpulkan dengan menerapkan prinsip-prinsip etnografi. Data selanjutnya diklasifikasi dan ditipifikasi sehingga terwujud tipe-tipe data yang siap untuk dikenai metode dan teknik analisis data. Metode analisis data yang digunakan adalah metode analisis padan kontekstual. Selain itu, metode analisis distribusional juga diterapkan untuk mendukung penerapan metode analisis padan kontekstual. Metode analisis padan dan metode analisis distribusional dilengkapi dengan teknik analisis yang lazim diterapkan dalam penelitian etnografi dan metode analisis ini. Manfaat teoretis penelitian ini adalah untuk menyempurnakan teori-teori ekolinguistik yang selama ini didasarkan pada teori-teori Barat. Manfaat praktisnya adalah untuk memaksimalkan perkuliahan ekolinguistik yang selama itu belum kontekstual di program-program magister. Hasil penelitian menunjukkan terdapatnya enam nilai kenomotetisan makna simbolis peranti pernikahan adat masyarakat NTT, dan masyarakat Jambi yang dikaji dengan perspektik
\end{abstract}


ekolinguistik metaforis. Keenam nilai simbolik yang bersifat nomotetis tersebut adalah: (1) nilai cinta kasih, (2) nilai ekonomis, (3) nilai kekeluargaan, (4) nilai keagungan, (5) nilai religius. Selanjutnya nilai-nilai simbolik keideosinkretisannya adalah: (1) nilai keharmonisan, (2) nilai ketulusan, (3) nilai pengharapan, (4) nilai penghormatan terhadap wanita.

Kata Kunci: kenomotetisan; keideosinkretisan; makna simbolik; ekolinguistik metaforis

\begin{abstract}
The study of language in relation to socio-cultural aspects in a metaphorical ecolinguistic perspective had not been done properly by Indonesian researchers. This metaphorical ecolinguistic research focused on the nomothetic symbolic and ideosynchronous values of traditional marriages in the provinces of East Nusa Tenggara and Jambi.The purpose of this study was formulated as follows: (1) describing the nomothetic values of traditional marriage equipments of the people of East Nusa Tenggara (NTT) and Jambi societies; (2) describing the ideosyncretic values contained in the traditional marriage tools of the people of NTT and Jambi societies? Data was collected by applying the listening method and the interview method. In addition, data are also collected by applying ethnographic principles in anthropology. The data collected are then classified and typified to realize the types of data that are ready to be subjected to data analysis methods and techniques. The data analysis method used in this research is the contextual equivalent analysis method. In addition, the distributional analysis method is also applied to support the application of the contextual equivalent analysis method. The equivalent analysis method and the distribution analysis method are complemented by analytical techniques commonly used in ethnographic research. The theoretical benefit of this research is to perfect ecolinguistic theories that have been based on Western theories. The practical benefit is to maximize ecolinguistic lectures which bave not been contextual in the master's programs. The results of this research showed that there were six values of symbolic meaning of the traditional marriage tools of the NTT community, and that of the people of Jambi which were studied with a metaphorical ecolinguistic perspective. The six symbolic values that are nomothetic in nature are conveyed as follows: (1) the value of love, (2) economic value, (3) family value, (4) grandeur value, (5) religious value. Furthermore, the symbolic values of traditional marriage in the two communities have the following ideological ideals: (1) harmony, (2) sincerity, (3) expectation, (4) respect for women.
\end{abstract}

Keywords: nomothetics; ideosyncratic; symbolic meaning; metaphorical ecolinguistics

\title{
PENDAHULUAN
}

Studi bahasa dalam kaitan dengan aspek-aspek sosial-budaya dalam perspektif ekolinguistik metaforis masih belum banyak dilakukan para peneliti Indonesia (Scott-Phillips, 2017; Rahardi, R. Kunjana., Setyaningsih, 2019). Penelitian ini dapat dianggap sebagai salah satu upaya menanggapi kelangkaan penelitian seperti disebutkan di depan itu. 
Dalam perspektif Pierce, tanda dapat dibedakan menjadi tiga, yakni ikon, indeks, dan simbol (Jakobson, 1965; Preucel and Bauer, 2001). Secara lebih teperinci, Pierce membedakan ketiga jenis tanda tersebut sebagai berikut: 'An Icon has a physical resemblance to the signified, the thing being represented. A photograph is a good example as it certainly resembles whatever it depicts. An Index shows evidence of what's being represented. A good example is using an image of smoke to indicate fire. A Symbol has no resemblance between the signifier and the signified. The connection between them must be culturally learned. Numbers and alphabets are good examples. There's nothing inherent in the number 9 to indicate what it represents. It must be culturally learned.' Di dalam makna simbolis dikenal dua jenis makna, yakni makna yang bersifat nomotetis (nomothetic) dan makna yang bersifat ideosinkrtetis (ideosyncretic). Sesuatu yang sifatnya nomotesis memiliki sejumlah aspek yang menyamakan (Duranti, 2001; Adu-Amankwah and McDowell, 2003). Adapun dalam sesuatu yang ideosinkretis terdapat banyak hal yang khusus dan spesifik.

Pada masyarakat NT'T terdapat peranti-peranti khusus yang digunakan dalam upacara adat pernikahan, secara umum adalah penggunaan busana adat daerah. Namun, tiap daerah memiliki peranti-peranti khusus, misalnya di Manggarai wajib mengenakan songke (kain tenunan derah Manggarai), sapu (khusus laki-laki yang dikenakan di kepala), bali belo (khusus mempelai perempuan yang dikenakan di kepala). Selain itu, ada juga loce (tikar) dan tange wa'i (bantal kaki), raci (pinang), kala (daun sirih), tahang (kapur sirih), tuak (sopi), dan lain-lain yang wajib ada dalam upacara pernikahan. Prosesi lamaran di Jambi disebut sebagai anter tando (antar tanda). Sebelum diadakan acara lamaran, biasanya akan ada utusan dari pihak laki laki, yang akan bertanya atau bersilahturahmi ke keluarga wanita. Dua malam menjelang hari pernikahan, kedua calon mempelai mempersiapkan diri untuk mengikuti prosesi malam batangas, yaitu mandi uap. Selain itu, calon mempelai wanita menjalani malam berinai, memeriahkan kuku dengan daun pacar. Sebelum prosesi Akad Nikah, calon mempelai wanita menunjukkan kemahirannya membaca Al-Qur'an.

Ekolinguistik adalah bidang interdisipliner linguistik. Dikatakan sebagai bidang interdisipliner karena di dalamnya terkandung dua bidang ilmu, yakni linguistik dan bidang ekologi. Ekologi yang dimaksud dibedakan menjadi dua, yakni lingkungan yang bersifat naturalistik dan lingkungan yang bersifat sosial (Gerbig, 2003, Kravchenko, 2016). Ekolinguistik yang berdimensi fisik lazim disebut dengan envirolinguistik, sedangkan ekolinguisitk yang berdimensi sosial lazim disebut ekolinguistik metaforis (Rahardi, 2017a).

Tujuan penelitian ini adalah, (1) mendiskripsikan nilai-nilai nomotesis yang terdapat dapam pernikahan adat masyarakat provinsi NTT dan provinsi Jambi; (2) mendeskripsikan nilai-nilai ideosinkretis yang terdapat dalam pernikahan adat masyarakat provinsi NTT dan provinsi Jambi? 


\section{METODE}

Penelitian nilai-nilai simbolis peranti-peranti pernikahan adat yang berperspektif ekolinguistik metaforis ini berjenis kualitatif (Jacobs, 2017, Félix-Brasdefer, 2015). Data penelitian ini dikumpulkan dengan menerapkan metode simak dan metode cakap sebagaimana metode yang lazim diterapkan dalam penelitian linguistik. Selain itu data juga dikumpulkan dengan menerapkan prinsip-prinsip etnografi (Science et al., 2017). Data yang terkumpul selanjutnya diklasifikasi dan ditipifikasi sehingga terwujud tipe-tipe data yang siap dikenai metode dan teknik analisis data. Adapun metode analisis data yang digunakan dalam penelitian ini adalah metode analisis padan kontekstual (Sudaryanto, 2015). Selain itu, metode analisis distribusional juga diterapkan untuk mendukung penerapan metode analisis padan kontekstual. Metode analisis padan dan metode analisis distribusional tersebut dilengkapi dengan metode dan teknik analisis yang lazim diterapkan dalam penelitian etnografi (Rahardi, 2017b).

Hasil sementara penelitian awal untuk pelaksanaan penelitian ekolinguistik metaforis ini menunjukkan bahwa nilai-nilai kearifan lokal dalam upacara-upacara adat di kedua provinsi yang dijadikan sumber data lokasional penelitian ini memiliki makna-makna simbolis yang bersifat nomotetis. Artinya, terdapat kesamaaan makna simbolis sekalipun keduanya tidak dapat dipandang memiliki akar budaya yang sama. Adapun nilai-nilai keideosinkretisan makna-makna simbolis penelitian ini akan dijelaskan lebih lanjut setelah pelaksanaan penelitian ini berakhir.

\section{HASIL DAN PEMBAHASAN}

Sesuai dengan rumusan masalah yang disampaikan pada bagian terdahulu, terdapat dua hal yang disampaikan pada bagian ini, yakni ihwal kenomotetisan dan keideosinkretisan nilai-nilai simbolis peranti-peranti pernikahan adat provinsi Jambi dan provinsi Nusa Tenggara Timur. Paparan kedua hal tersebut disampaikan sebagai berikut.

\section{Kenomotetisan Makna Simbolik Pernikahan Adat Masyarakat N'T'T dan Masyarakat Jambi}

Seperti telah disampaikan sebelumnya, bahwa setiap langkah dalam upadara adat pernikahan di Provinsi Jambi dan NTT, memiliki nilai-nilai yang sifatnya dimiliki secara bersama-sama. Dalam hal ini, makna-makna simbolik dalam upacara adat tersebut memiliki kesamaan atau kemiriban makna. Dalam penelitian ini, kesamaan atau kemiripan makna yang demikian itu disebut sebagai kenomotetisan. Dari penelitian yang telah dilakukan, nilainilai nomotetis yang terdapat dalam upacara adat pernikahan di kedua provinsi tersebut dipaparkan sebagai berikut. 


\section{a. Nilai Cinta Kasih}

Dalam upacara adat pernikahan di kedua provinsi tersebut, nilai cinta kasih itu diungkapkan dalam wujud cincin. Dalam bahasa NTT, cincin sebagai lambang nilai simbolik cinta kasih tersebut digunakan untuk mengungkapkan nilai kasih sayang atau nilai cinta kasih (Locher, 2013). Dalam perspektif masyarakat di NTT, cinta kasih yang ditandai dengan kata momang yang bermakna 'mengasihi'dalam ungkapan yang disampaikan ketika kedua mempelai itu saling mengenakan cincin. Wujud cinta kasih yang terungkap dalam bentuk cincin tersebut di dalam masyarakat Jambi dimaknai dengan ungkapan, "kalau ingin ikatan cinta berumur abadi, masukkan set cincin pernikahan dalam hantaran atau seserahan yang merupakan wujud doa pengikat kedua pasangan agar selalu hidup bersama sampai maut memisahkan'.

Dalam pernikahan adat Manggarai hanya terdapat satu cincin, yakni yang dikenakan kedua mempelai saat acara tukar cincin, sedangkan di pernikahan adat jambi, ada dua cincin, yaitu cincin saat lamaran dan pernikahan. Cincin saat lamaran hanya dikenakan pada mempelai wanita, sedangkan saat acara pernikahan cincin dikenakan oleh kedua memepelai. Dari segi konteks penggunaan cincin kedua daerah ini memang berbeda, namun dari segi pemaknaan dan nilai sama, yakni nilai cinta kasih (Chen, 2017). Nilai cinta kasih diketahui dari pemaknaannya, yaitu kata momang (mengasibi) dan hidup bersama sampai maut memisahkan. Dengan demikian dapat ditegaskan bahwa 'cincin' atau 'kila' sebagai salah satu peranti yang digunakan dalam upacara pernikahan adat memiliki nilai simbolik nomotetik. Bahkan mungkin bukan hanya di kedua wilayah di luar Jawa itu, di wilayah-wilayah lainnya pun seperti halnya Jawa, cincin memiliki 'perlambang' atau makna simbolik kasih sayang.

\section{b. Nilai Ekonomis}

Nilai ekonomis dalam upacara pernikahan adat di wilayah Jambi dan wilayah NT'T terdapat dalam wujud uang. Uang itulah yang lazim disebut sebagai mahar. Besar kecilnya mahar tergantung pada latar belakang sosial-budaya masing-masing (Cuddy et al., 2015). Di dalam masyarakat Jawa, misalnya, mahar itu tidak selalu dalam jumlah uang yang banyak, tetapi bisa saja dijadikan sebagai simbol bahwa seseorang telah 'ditebus' untuk dijadikan teman hidup bersama dalam ikatan keluarga sebagai suami-istri. Dalam agama tertentu juga demikian, mahar itu tidak selalu berjumlah banyak tetapi memiliki makna simbolis tertentu, misalnya sesuai dengan angka tahun, bulan, dan tanggal tertentu.

Dalam masyarakat NT'T, mahar itu berupa uang atau 'seng'. Berbeda dengan yang disampaikan di atas, besaran uang biasa ditentukan berdasarkan berbagai pertimbangan, dia antaranya harga bahan pangan dan taraf pendidikan anak. Jadi jika seseorang berpendidikan tinggi, maka nilai 
maharnya pasti akan jauh lebih besar daripada seseorang yang berlatar belakang pendidikan rendah. Selain karena latar belakang pendidikan, besarkecilnya mahar juga ditentukan oleh situasi atau keadaan ekonomi yang terjadi pada saat upacara adat dilangsungkan.

Dimensi kenomotetisan tentang nilai ekonomis mahar yang demikian itu juga terjadi di dalam upacara adat pernikahan Jambi. Mengingat bahwa yang dicari aspek kenomotetisannya adalah upacara adat yang terjadi di provinsi Jambi dan provinsi NTT, dan terbukti bahwa di kedua wilayah tersebut kesamaan nilai simbolik tersebut terjadi, maka dapat ditegaskan bahwa dalam kaitan dengan nilai ekonomis uang pernikahan, kedua wilayah tersebut memiliki dimensi kenomotetisan (Luardini and Simbolon, 2016, Rahardi, 2010).

\section{c. Nilai Kekeluargaan}

Baik di wilayah provinsi NTT maupun provinsi Jambi, nilai simbolik kekeluargaan disimbolkan dalam wujud daun sirih dan pinang. Dalam konteks NTT, kedua peranti di dalam upacara adat tersebut disebut sebagai 'kala agu raci' yang maknanya tentu saja adalah 'sirih dan pinang'. Dalam konteks perikahan di provinsi Jambi, sebutannya sama dengan wilayahwilayah lain, seperti misalnya Jawa, yakni 'sirih dan pinang'. Di wilayah Jambi, sirih dan pinang itu dapat dimanfaatkan sebagai peranti komunikasi. Maksudnya adalah komunikasi di antara kedua belah pihak sebagai manifestasi perkenalan dalam koridor kekeluargaan (Helliwell \& Putnam, 2004).

Di wilayah NTT, nilai kekeluargaan tersebut dapat dilihat dari konteks dan makna sirih dan pinang itu sendiri. Hal serupa juga terjadi di Jambi bahwa sirih dan pinang digunakan sebagai alat komunikasi. Dalam pemanfaatannya, sirih dan pinang tersebut digunakan bersama-sama dengan kapur sirih, tembakau, serta pinang, yang diletakkan di tempat sirih. Di dalam masyarakat NTT dan Jambi, sirih dan pinang itu menunjukkan makna simbolik persaudaraan. Jadi jelas sekali bahwa di kedua wilayah tersebut, nilai kekeluargaan dan nilai persaudaraan itu diwujudkan dalam bentuk sirih dan pinang.

\section{d. Nilai Estetika}

Pernikahan adat di wilayah manapun, sesungguhnya selalu memiliki nilai estetis atau nilai keindahan. Nilai kestetisan itu terkait dengan sifat pernikahan itu sendiri yang bersifat agung, indah, dan lazimnya menarik untuk diperhatikan dan dirayakan oleh sesama. Dalam pernikahan adat NTT, khususnya Manggarai, busana yang lazim digunakan untuk mendukung keestetikan itu adalah Songke, kebaya, destar dan balibelo. Masyarakat Manggarai beranggapan bahwa apabila busana-busana ini tidak dikenakan saat upacara pernikahan, maka upacara dipandang tidak indah dan tidak 
agung. Songke pada acara pernikahan adat Manggarai dikenakan oleh kedua mempelai dan orang yang hadir dalam uapacara tersebut.

Kebaya hanya dikenakan oleh wanita, baik mempelai wanita maupun para wanita yang hadir dalam acara, baik anak muda maupun ibu-ibu. Balibelo adalah perhiasan khas Manggarai untuk wanita. Balibelo dikenakan di kepala mempelai wanita. Sementara itu, sapu (destar) dikenakan oleh pria, baik mempelai pria maupun para undangan. Berbeda dengan yang digunakan di wilayah provinsi NTT khususnya Manggarai, yang digunakan di dalam pernikahan adat Jambi adalah kain songket. Songket pada saat lamaran digunkan oleh kedua belah pihak mempelai. Sarung songket dan selendang merah yang terbuat dari tenunan benang sutra sebagai pelengkapnya.

Jadi jelas sekali kelihatan bahwa di dalam upacara adat tersebut dikenakanlah kain yang dianggap paling bagus, yakni yang terbuat dari benang sutera. Perspektif bahwa nilai-nilai estetika itu hendaknya dikedepankan dalam pernikahan adat terefleksi dalam pemanfaatan jasa dari para perias unggul dan penyewa-penyewa pakaian adat, yang selanjutnya digunakan dalam pelaksanaan pernikahan adat tersebut (Hodgkin, 2003). Bukan saja terjadi di kedua wilayah tersebut, bahkan di setiap peristiwa pernikahan di dunia ini, pakaian-pakaian yang indah dan rias-rias yang unggul diupayakan oleh keluarga kedua mempelai (Rahardi, 2009).

\section{e. Nilai Keagungan}

Nilai keagungan pasti diupayakan untuk dapat hadir dalam setiap peristiwa pernikahan adat di manapun. Artinya, nilai keangungan ini harus dianggap sebagai nilai yang sifatnya nomotetis karena merupakan nilai yang diupayakan hadir dalam setiap persitiwa pernikahan di wilayah manapun. Di dalam masyarakat Jawa, misalnya saja, digunakanlah penutup kepala yang disebut dengan 'blangkon'. Blankon sebagai penutup kepala digunakan secara serasi dengan pakaian 'beskap' untuk model Solo atau Surakarta, dan digunakan bersama dengan pakaian 'sorjan'untuk pernikahan adat Jawa Yogyakarta. Jadi 'blankon' itu tidak selayaknya digunakan bersama dengan pakaian yang sekenanya, seperti misalnya berbaju lengan panjang berdasi, lalu bersarung dll. Dalam masyarakat NT'T, khususnya Manggarai, dikenakanlah sapu (destar) oleh para pria di kepala. Sapu tersebut dikenakan baik oleh mempelai pria maupun para undangan, tentu saja dengan kualitas dan ornamen yang berbeda.

Sedangkan di dalam pernikahan adat Jambi, dikenakanlah penutup kepala yang bernama lacak. Penutup kepala itu terbuat dari kain beludru merah yag pada bagian dalamnya diberi kertas karton. Pemberian kertas karton tersebut dimaksudkan agar kain dapat ditegakkan hingga menjulang ke atas. Makna simbolik dibalik pemakaian lacak yang berdiri ke atas tersebut menunjuk pada dimensi keagungan (Mills, 2009), (Rahardi, 2018b). Dengan demikian dapat ditegaskan bahwa nilai simbolik yang bersifat nomotetis dari pemanfaatan penutup kepala yang berbeda-beda manifestasinya di berbagai 
wilayah tersebut, termasuk di wilayah provinsi NTT dan provinsi Jambi, adalah nilai simbolik keagungan. Sejumlah referesi menyebutkan bahwa hal tersebut berkaitan dengan kepimimpinan, tetapi penulis lebih melihat bahwa nilai yang bersifat nomotetis tersebut adalah nilai keagungan.

\section{f. Nilai Religius}

Hampir semua pernikahan di dalam masyarakat Indonesia tidak dapat dilepaskan dari nilai-nilai agama yang dianut oleh pasangan pengantin yang sedang melakukan pernikahan tersebut. Dalam pernikahan adat pada masyarakat di rovinsi Jambi, misalnya saja, nilai-nilai keagamaan itu termanifstasi dalam Alquran dan seperangkat alat shalat. Terdapat tiga hal yang pokok yang perlu disebutkan, yakni Alquran, Mukenah, dan Sajadah. Alquran sebagai pedoman agama yang menuntun kedua belah pihak dalam pernikahan yang sakinah mawadah dan warohmah. Mukenah sebagai pakaian penutup untuk menutupi tubuh calon mempelai perempuan guna menjaga aurat. Sajadah sebagai simbol untuk bersujud berserah diri Kepada Allah SWT.

Hal serupa terjadi pula pada masyarakat di provinsi NT"T, khususnya Manggarai dengan warga masyarakat yang umumnya beragama Kristen Katholik, kereligiusan pernikahan adat tersebut diungkapkan pula dengan perangkat kitab suci agama Kristen Katholik, yakni Injil, dengan perantiperanti lain yang menjadi nilai-nilai religius tambahan seperti halnya salib, rosario, dan peranti-peranti lainnya yang diberkati oleh Imam sebagai pejabat gereja yang akan mengesahkan pernikahan tersebut (Haviland et al., 2011; R. Kunjana Rahardi, 2018a).

Dengan demikian bahwa pernikahan adat di NTT, khususnya Manggarai, memiliki nilai-nilai nomotetis kereligiusan yang dimilikui secara sama. Perbedaan iman dan keyakinan sajalah yang menjadikan seolah-olah nilai religius tersebut berbeda, padahal sesungguhnya kedua-duanya adalah sama. Pun jika terjadi pada pasangan-pasangan lain dengan keyakinan yang tidak sama, dipastikan nilai-bilai religius tersebut akan dapat diidentifikasi di dalamnya.

\section{Keideosinkretisan Makna Simbolik Pernikahan Adat Masyarakat NTT dan Masyarakat Jambi}

Ideosinkretis artinya bersifat khusus, khas, spesifik, atau tidak bersifat umum. Dengan demikian makna kata ideosinkretis itu berlawanan dengan maka kata nomotetis. Dari penelitian yang telah dilakukan, terdapat sejumlah nilai keideosinkretisan nilai simbolis pelaksanaan pernikahan adat di wilayah provinsi NTT dan wilayah provinsi Jambi. Pada bagian berikut, hal-hal yang bersifat ideosinkretis tersebut dipaparkan satu demi satu. 


\section{a. Nilai Keharmonisan}

Nilai keharmonisan dalam pernikahan adat pada masyarakat provinsi NTT sangat kelihatan pada pemakaian busana. Busana yang sangat lazim ditemukan dalam pernikahan adat tersebut adalah, Songke, Kebaya, Sapu (destar), Balibelo. Songke pada acara pernikahan adat Manggarai dikenakan oleh kedua mempelai dan orang yang hadir dalam upacara tersebut. Kebaya hanya dikenakan oleh wanita, baik mempelai wanita maupun para wanita yang hadir dalam acara, baik anak muda maupun ibu-ibu. Balibelo adalah perhiasan khas Manggarai untuk wanita. Balibelo dikenakan di kepala mempelai wanita. Sementara itu, sapu (destar) dikenakan oleh pria, baik mempelai pria maupun para undangan. Songke, kebaya, destar dan balibelo adalah konsep busana masyarakat Manggarai untuk pernikahan adat. Masyarakat Manggarai beranggapan bahwa apabila busana-busana ini tidak dikenakan saat upacara pernikahan, maka upacara dipandang tidak indah dan tidak agung.

Hal demikian itu tidak ditemukan dalam masyarakat provinsi Jambi ketika sedang terdapat peristiwa pernikahan adat. Dalam masyarakat provinsi Jambi, busana yang dikenakan bukan pertama-tema mengedepankan nilai simbolik keharmonisan seperti halnya pada masyarakat Manggarai, melainkan nilai simbolik keindahan (Limberg, 2015; Miller, 2017). Dalam masyarakat Jambi, busana yang digunakan adalah kain kebaya dan kain songket. Kebaya merupakan pakaian tradisional yang dikenakan pada pengantin perempuan, sedangkan songket merupakan pakaian tradisional yang berasal dari masyarakat Jambi. Dengan demikian tidak terdapat nilai-nilai kenomotetisan melainkan nilai-nilai keideosinkretisan.

\section{b. Nilai Ketulusan}

Dalam pernikahan adat di masyarakat provinsi NTT, khususnya Manggarai, terdapat minuman 'tuak'. Tuak digunakan ketika melakukan ritual kapok sundung dan kepok kapung. Kepok sundung dilakukan untuk menerima tamu (keluarga mempelai laki-laki) yang datang. Kapok sundung adalah sapaan adat dalam ritual penyambutan. Goet dalam kapok sundung: woko poli ngasang koal agu cai kapok sundung ite. Sementara itu, kapung berarti memangku seseorang. Dalam hal ini kepok kapung bertujuan menerima dan merangkul keluarga yang datang. Goet dalam kapok kapung: woko oto nepe berit tange, kepok tuak. Tuak, yaitu minuman beralkohol yang dibuat dari nira aren yang diragikan melambangkan kesejukan hati bagi masyarakat Manggarai. Tuak digunakan seabagai sarana komunikasi dalam upacara adat Manggarai.

Hal demikian ini tidak terdapat dalam pernikahan adat pada masyarakat Jambi. Nilai ketululusan dalam masyarakat provinsi Jambi ketika menerima warga baru yang saat itu menjadi pengantin bukan dengan minum tuak, tetapi tentu dengan cara lain yang menunjukkan pula keideosinkretisan (Gintis, 2016). Dalam masyarakat tersebut terdapat peranti pernikahan adat yang disebut dengan ayak kodok. Ayam kodok telah diyakini sejak nenek moyang sebagai berantara doa dalam prosesi pernikahan adat Jambi. Di dalam 
sosok ayak kodok itulah dimensi-dimensi ketulusan hadir. Jadi jelas bahwa nilai keideosinkretisan yang terdapat di masyarakat provinsi NTT dan masyarakat provinsi Jambi dalam mengungkapkan nilai ketulusan sangat berbeda.

\section{c. Nilai Pengharapan}

Di dalam pernikahan adat masyarakat provinsi NTT, khususnya manggarai, nilai keideosinkretisan 'pengharapan', khususnya akan hadirnya generasi baru sebagai penerus estafet kehidupan, dimanifestasikan dalam peranti pernikahan yang berupa Ruba manuk kampong atau telur ayam kampung. Telur ayam kampung digunakan dalam upacara Podo. Podo adalah upacara pengahantaran mempelai wanita ke keluarga laki-laki. Dalam upacara ini, telur ayam diletakan tepat di pintu rumah laki-laki untuk diinjak oleh mempelai perempuan. Telur ayam mengandung makna simbolik, yakni keturunan (Alexander, 2006). Dengan demikian dapat ditegaskan bahwa nilai pengharapan inilah yang menjadi salah satu nilai ideosinkretik masyarakat provinsi NTT. Hal tersebut tidak ditemukan dalam pernikahan adat masyarakat provinsi Jambi. Jadi dapat ditegaskan bahwa 'ruha manuk kampong' adalah salah satu manifestasi keideosinkfetisan pernikahan adat Manggarai.

\section{d. Nilai Penghormatan terhadap Wanita}

Secara historis, zaman dulu masyarakat Manggarai jarang memegang uang. Namun masyarakat Manggarai kaya akan hasil tani dan ternak. Hewan yang memiliki nilai jual sangat tinggi adalah kerbau dan kuda, sehingga kerbau dan kuda digunakan sebagai mahar pernikahan. Untuk menghargai atau menghormati wanita, juga orang tua dari wanita itu, maka hewan yang digunakan ialah hewan yang memiliki nilai yang "tinggi" pula. Seberapa tinggi mertabat wanita sesungguhnya tampak dengan jelas dengan mahar yang berupa kerbau dan kuda ini. Kedua hewan piaraan tersebut sangat mahal, dan nilainya dapat digunakan untuk mengormati sosok perempuan yang bakal diperistri oleh seorang laki-laki di dalam masyarakat tersebut (Kramsch, 2011). Dalam tradisi masyarakat provinsi NTT, khususnya Manggarai, mahar dalam bentuk hewan itu disebut dengan paca. Mahar dalam masyarakat provinsi Jambi tidak sama dengan yang terjadi pada masyarakat provinsi NT'T. Jadi jelas sekali kelihatan bahwa dalam pernikahan adat provinsi NT'T, wanita mendapatkan tempat yang benar-benar istimewa karena 'mahal' nilainya, dan karenanya mahal pula martabatnya.

\section{KESIMPULAN}

Sebagai simpulan dapatlah ditegaskan kembali bahwa sedikitnya terdapat enam nilai kenomotetisan dalam pernikahan adat masyarakat provinsi NTT, khususnya Manggarai dan masyarakat provinsi Jambi yang dikaji dengen perspektik ekolinguistik metaforis. Keenam nilai simbolik yang 
bersifat nomotetis tersebut dapat disampaikan sebagai berikut: (1) nilai cinta kasih, (2) nilai ekonomis, (3) nilai kekeluargaan, (4) nilai keagungan, (5) nilai religius. Selanjutnya nilai-nilai simbolik pernikahan adat di kedua provinsi tersebut memiliki nilai-nilai keideosinkretisan sebagai berikut: (1) nilai keharmonisan, (2) nilai ketulusan, (3) nilai pengharapan, (4) nilai penghormatan terhadap wanita.

Selanjutnya perlu ditegaskan bahwa penelitian ini memiliki keterbatasan dalam hal pelaksanaan pencatatan atau etnografi. Ketua penelitian ini memerantikan tenaga pengumpul data yang dilakukan secara etnografis sebanyak dua orang mahasiswa program magister. Hal ini dipandang sebagai keterbatasan karena dengan pemerantian tenaga pengumpul data tersebut, peneliti utama tidak dapat sepenuhnya menghadirkan data yang optimal secara etnografis. Hasil penelitian ini tentu sangat bermanfaat bagi pengembangan ekolinguistik, baik yang bersifat naturalistik maupun yang bersifat metaforis. Oleh karena itu, penelitian serupa dengan objek yang berbeda akan sangat baik jika dapat dilaksanakan dalam waktu yang tidak begitu lama.

\section{UCAPAN TERIMA KASIH}

Para penulis mengucapkan terima kasih kepada LPPM Universitas Sanata Dharma Yogyakarta atas dana penelitian internal yang disampaikan. Selain itu, penulis mengucakan terima kepada mitra bestari atas masukan dan saran yang disampaikan untuk penyempurnaan artikel ini.

\section{DAFTAR PUSTAKA}

Adu-Amankwah, D., \& McDowell, J. (2003). An ethnopragmatic study of jokes and joking in an Akan community. Folklore.

Alexander, J. C. (2006). Cultural pragmatics: Social performance between ritual and strategy. In Social Performance: Symbolic Action, Cultural Pragmatics, and Ritual. https://doi.org/10.1017/CBO9780511616839.002

Alwi, Soenjono Dardjowidjojo, Hans Lapoliwa, A. M. M. (1998). Tata Bahasa Baku Bahasa Indonesia. Departemen Pendidikan Dan Kebudayaan Republike Indonesia.

Budiarta, I. W., \& Kasni, N. W. (2017). The Concept of Animals in Balinese Proverbs. International Journal of Linguistics, Language and Culture (IJLLC). https://doi.org/10.21744/ijllc.v3i1.371

Chen, J. (2017). Research Trends in Intercultural Pragmatics. Australian Journal of Linguistics. https://doi.org/10.1080/07268602.2016.1204903

Cuddy, A. J. C., Wolf, E. B., Glick, P., Crotty, S., Chong, J., \& Norton, M. I. (2015). Men as cultural ideals: Cultural values moderate gender stereotype content. Journal of Personality and Social Psychology. https://doi.org/10.1037/pspi0000027 
Duranti, A. (2001). Linguistic anthropology a reader. Blackwell anthologies in social and cultural anthropology. https://doi.org/10.1525/jlin.1991.1.1.3

Enfield, N. J. (2009). Relationship thinking and human pragmatics. Journal of Pragmatics. https://doi.org/10.1016/j.pragma.2008.09.007

Félix-Brasdefer, J. C. (2015). Assessing Second Language Pragmatics. Journal of Pragmatics. https://doi.org/10.1016/j.pragma.2015.04.016

Gerbig, A. (2003). The Ecolinguistics Reader: Language, Ecology and Environment. Current Issues in Language Planning. https:// doi.org/10.1080/14664200308668051

Gintis, H. (2016). Homo Ludens: Social rationality and political behavior. Journal of Economic Behavior and Organization. https://doi.org/10.1016/j.jebo.2016.01.004

Gretsch, C. (2009). Pragmatics and integrational linguistics. Language and Communication. https://doi.org/10.1016/j.langcom.2009.02.010

Halliday, M. A. K. (1975). Learning how to mean : explorations in the development of language. Explorations in language study. https://doi.org/10.1016/B9780-12-443701-2.50025-1

Haviland, W. A., Prins, H. E. L., McBride, B., \& Walrath, D. (2011). Cultural anthropology: The buman challenge. Journal of Computer Information Systems. https://doi.org/10.1017/CBO9781107415324.004

Helliwell, J. F., \& Putnam, R. D. (2004). The social context of well-being. In Philosophical Transactions of the Royal Society B: Biological Sciences. https://doi.org/10.1098/rstb.2004.1522

Hodgkin, R. (2003). Homo Ludens. In The Passion to Learn: An Inquiry into Autodidactism. https://doi.org/10.4324/9780203329108

Jacobs, G. M. (2017). Ecolinguistics and education. In The Routledge Handbook of Ecolinguistics. https://doi.org/10.4324/9781315687391

Jakobson, R. (1965). Quest for the Essence of Language. Diogenes. https://doi.org/10.1177/039219216501305103

Kramsch, C. (2011). Language and culture. In The Routledge Handbook of Applied Linguistics. https:/ / doi.org/10.4324/9780203835654

Kravchenko, A. V. (2016). Two views on language ecology and ecolinguistics. Language Sciences. https://doi.org/10.1016/j.langsci.2015.12.002

Limberg, H. (2015). Principles for pragmatics teaching: Apologies in the EFL classroom. ELT Journal. https://doi.org/10.1093/elt/ccv012

Locher, M. A. (2013). Cyberpragmatics: Internet-Mediated Communication in Context. Journal of Pragmatics. https://doi.org/10.1016/j.pragma.2012.12.002

Luardini, M. A., \& Simbolon, M. (2016). Ecolinguistics for teaching English. Asian EFL Journal.

Miller, V. (2017). Phatic culture and the status quo: Reconsidering the purpose of social media activism. Convergence. https://doi.org/10.1177/1354856515592512

Mills, S. (2009). Impoliteness in a cultural context. Journal of Pragmatics. 
https://doi.org/10.1016/j.pragma.2008.10.014

Peace, A., \& Mühlhäusler, P. (2006). Environmental Discourses. Annual Review of Anthropology. https://doi.org/10.1146/annurev.anthro.35.081705.123203

Preucel, R. W., \& Bauer, A. A. (2001). Archaeological Pragmatics. Norwegian Archaeological Review. https://doi.org/10.1080/00293650127469

Rahardi, R. Kunjana., Setyaningsih, Y. (2019). Contextualizing Local Values of Children's Games in the Perspective of Ecopragmatics to Enhance Culture-Specific Based Communication. International Journal of Engineering and Advanced Technology (IJEAT), 9(Issue-1, October 2019), 143-151. https://doi.org/DOI: 10.35940/ijeat.A1096.109119

Rahardi, R. K. (2009). Pragmatik: Kesantunan imperatif bahasa Indonesia. Jakarta: Erlangga.

Rahardi, R. K. (2010). Sosiopragmatik (1st ed.). Jakarta: Erlangga.

Rahardi, R. K. (2017a). Linguistic Impoliteness in The Sociopragmatic Perspective. Jurnal

Humaniora. https:// doi.org/10.22146/jh.v29i3.24954

Rahardi, R. K. (2017b). Pragmatic Phenomena Constellation in Specific Culture Dimension Language Study. International Journal of Humanity Studies, 1(1), 84-92. https://doi.org/doi.org/10.24071/ijhs.2017.010109

Rahardi, R. K. (2018a). Elemen dan Fungsi Konteks Sosial, Sosietal, dan Situasional dalam Menentukan Makna Pragmatik Kefatisan Berbahasa. In Prosiding Seminar Tabunan Linguistik Universitas Pendidikan Indonesia (SETALI 2018) (pp. 654-658). Bandung: Sekolah Pascasarjana Universitas Pendidikan Bandung.

Rahardi, R. K. (2018b). Konstelasi Kefatisan dalam Teks-teks Natural Religius dengan Latar Belakang Kultur Spesifik. In Prosiding Kongres Internasional Masyarakat Linguistik Indonesia 2018 (pp. 274-279). Manokwari, Papua Barat: MLI.

Rahardi, R. K., Setyaningsih, Y., \& Dewi, R. P. (2019). Iconic Meanings of Traditional Herbs and Shrubs: Culture-Specific Based Envirolinguistic Perspective, (2), 1986-1992. https://doi.org/10.35940/ijeat.B2530.129219

Science, L., Company, P., Long, M. H., Canagarajah, S., Peterson, R. A., Nagel, J., ... Backus, A. (2017). An Introduction to Discourse Analysis: Theory and Method. Journal of Pragmatics. https://doi.org/10.1016/0346-251X(88)90022-X

Scott-Phillips, T. C. (2017). Pragmatics and the aims of language evolution. Psychonomic Bulletin and Review. https://doi.org/10.3758/s13423-0161061-2

Sudaryanto. (2015). Metode dan Aneka Teknik Analisis Bahasa: Pengantar Penelitian Wahana Kebudayaan secara Linguistis (1st ed.). Yogyakarta: Sanata Dharma University Press. 
van Dijk, T. A. (2008). Discourse and context: A sociocognitive approach. Discourse and Context: A Sociocognitive Approach. https://doi.org/10.1017/CBO9780511481499

Wimberley, E. T. (2017). Ecopragmatics. Ecopragmatics. https://doi.org/10.18848/978-1-61229-613-5/cgp 